\title{
Interannual Variation of the Fall Rainfall in Central Vietnam
}

\author{
Ming-Cheng YEN \\ Department of Atmospheric Sciences, National Central University, Chung-Li, Taiwan \\ Tsing-Chang CHEN
}

Atmospheric Science Program, Department of Geological and Atmospheric Sciences, Iowa State University, Ames, Iowa

\author{
Hao-Lin HU, Ren-Yow TZENG \\ Department of Atmospheric Sciences, National Central University, Chung-Li, Taiwan \\ DINH Duc Tu, NGUYEN Thi Tan Thanh \\ Aero-Meteorological Observatory, Vietnam National Hydro-Meteorological Services, Hanoi, Vietnam \\ and \\ Chow Jeng WONG \\ School of Physics, Universiti Sains Malaysia, Malaysia
}

(Manuscript received 31 May 2010, in final form 22 October 2010)

\begin{abstract}
The twenty nine years (1979-2007) rain-gauge based gridded precipitation data generated by the Asian Precipitation-Highly Resolved Observational Data Integration Towards Evaluation of water resources (APHRODITE) are used to depict the rainfall climatology in Vietnam. The rain gauge observations of 163 stations in Vietnam for year 2007 are employed to validate the analysis results of the APHRODITE precipitation and to verify two distinct rainfall regimes: the October-November regime in central Vietnam and the MayOctober regime in the northern and southern part of this country identified with APHRODITE data. It appears that the Truong Son Range along the western border of Vietnam with Laos and Cambodia provides a natural separation of the October-November rainfall regime in central Vietnam from others. The interannual variation of the October-November rainfall regime can be well depicted by a principal mode obtained from the empirical orthogonal function analysis on the 29-year-APHRODITE precipitation. Time variation of this interannnual mode is out-of-phase with the SST(NINO3.4) index. It is inferred from this negative correlated relationship that central Vietnam is drier (wetter) when the SSTs over the NINO3.4 region is warmer (colder). It is found from the water vapor transport analysis that an anomalous cyclonic (anticyclonic) circulation over south Asia is paired with an anomalous anticylonic (cyclonic) circulation over the western north Pacific during cold (warm) episodes. Water vapor is converged (diverged) by these two anomalous circulations toward (out of) the South China Sea and Philippine Sea west of $150^{\circ} \mathrm{E}$ during cold (warm) years. In turn, the anomalous cyclonic (anticyclonic) circulation
\end{abstract}

Corresponding author address: Ming-Cheng Yen, Department of Atmospheric Sciences, Rm. S1-707, National Central University, Chung-Li 32001, Taiwan.

E-mail: tyenmc@atm.ncu.edu.tw

(C) 2011, Meteorological Society of Japan 
in South Asia enhances (reduces) the water vapor supply to Indochina, particularly to Vietnam. Coupling with this pair of anomalous circulations, water vapor is converged (diverged) by the anomalous divergent circulation, coupling with the aforementioned pair of anomalous circulation, toward (out of) Southeast Asia to maintain excessive (deficient) rainfall during cold (warm) episodes. Evidently, the response of the divergent circulation to the tropical Pacific SST anomalies contributes to the interannual variation of the October-November rainfall in central Vietnam.

\section{Introduction}

Located along the coast of Indochina, Vietnam stretches from the northern part of southeast Asia to the tropics. The climate of this country is regulated by two distinct Asian monsoons: the northeast winter and the southwest summer monsoons. During the southwest summer (JJA) monsoon season, major rainfall appears in the northern part of Southeast Asia (including northern Vietnam) and East Asia (Ramage 1952; Chen et al. 2004). Due to the orographic effect of the northwest-southeast oriented Truong Son Range sitting along the western border of Vietnam with Laos and Cambodia, less rainfall occurs on the leeward side of central Vietnam (Fig. 1) as depicted by Chang et al. (2005). In boreal winter, the northeasterly monsoon brings the Southeast Asian countries south of $10^{\circ} \mathrm{N}$ about 50\% of their annual rainfall (Cheang 1987). On the contrary, not only Vietnam but also entire Indochina becomes cool dry season from midDecember till mid-April (Fig. 1). Following the seasonal transition from the boreal summer to the winter monsoon, the major rainy season in central Vietnam is induced by the southward migrating convection activities during fall (SON), particularly in October-November (Matsumoto 1997; Yokoi and Matsumoto 2008).

Using sparse daily rain gauge station data, Yokoi et al. (2007) were able to depict the large scale intraseasonal variation of precipitation over Indochina. However, numerous efforts were made to engage on case study either through observational analysis or numerical simulation (e.g., Yokoi and Matsumoto 2008; Truong et al. 2009) while others to aim at the interannual variation of precipitation in central Vietnam (Nguyen et al. 2007). Although these studies investigated rainfall in central Vietnam, the former examined the heavy rainfall cases north of $15^{\circ} \mathrm{N}$ whereas the latter explored those south of $15^{\circ} \mathrm{N}$. According to the flood record archived from the Dartmouth Flood Observatory (http://www .dartmouth.edu/ floods/index.html), most flooding events in central Vietnam covers the area between $12^{\circ} \mathrm{N}$ and $19^{\circ} \mathrm{N}$ (Chen et al. 2011). Thus, a compre- hensive analysis of the rainfall climatology in Vietnam with high-resolution station observations is needed. Recently, by gauge-based analysis a daily gridded precipitation dataset over Asia was compiled by Yatagai et al. (2009) with a dense gauge network. This dataset would provide a better understanding of the rainfall variation in Vietnam.

As revealed from numerous publications (e.g., Chen et al. 1998; Chen and Yoon 2000; Wang et al. 2000; Zhang et al. 2002), the interannual variation researches related to Indochina as a whole have always been focused on the summer monsoon season. Perhaps the lack of high-resolution rainfall data, the interannual variation of heavy rainfall during fall in Vietnam has not attracted too much research attention. Being the most significant effect on the global climate system (Webster et al. 1998), can the El Niño-Southern Oscillation (ENSO) have any pronounced impact on the Vietnam rainfall. During the ENSO warm (cold) summers, Chen et al. (1998) and Chen and Weng (1998, 1999) had shown the large-scale summer circulation in the Pacific basin that a summer anomalous wave train emanates from the western tropical Pacific along the rim of the North Pacific in response to the interannual variation of sea surface temperature (SST) in the tropical Pacific, which is known as PacificJapan (PJ) pattern suggested by Nitta (1987). Furthermore, Chen and Yoon (2000) demonstrated that the anomalous circulation cell of this shortwave train in the western tropical Pacific neither covers Indochina nor exerts a direct impact on the interannual variation of the Indochina summer monsoon rainfall. In fact, this rainfall variation is attributed to a modulation on the occurrence frequency of the westward-propagating synoptic disturbances across Indochina by the aforementioned anomalous circulation cell and the global anomalous divergent circulation in response to the SST anomalies in the tropical Pacific. During the extreme ENSO winter phases, a North Pacific shortwave train teleconnecting the climate systems of East Asia and North America is induced by the anomalous forcing formed by cold surge vortices over the Philippine Sea in response to the anoma- 


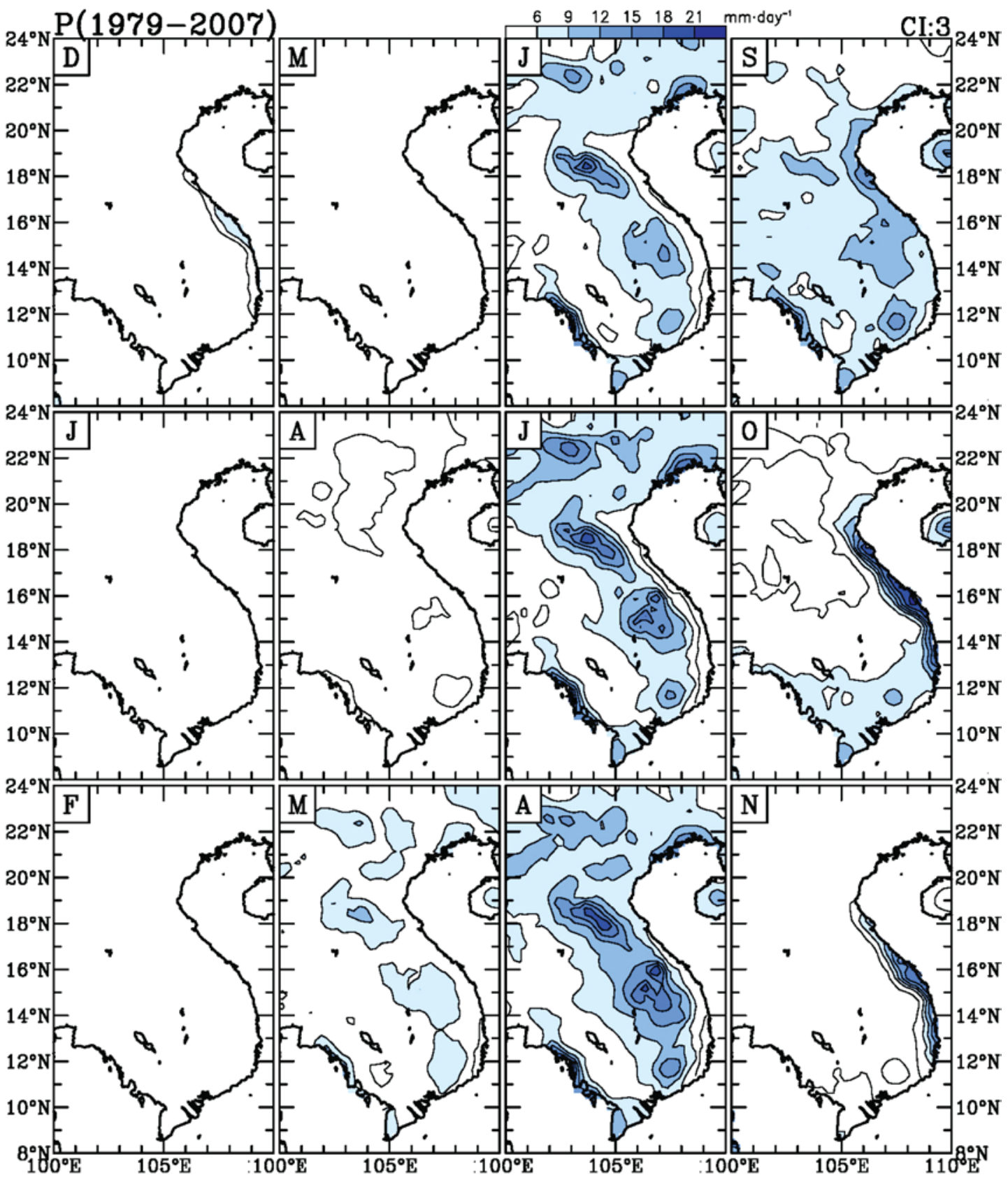

Fig. 1. Monthly mean climatology of Indochina Peninsula rainfall (averaged for the period of 1979-2007) generated from the rain-gauge based 0.25 degree daily grid precipitation product developed by the Asian Precipitation-Highly Resolved Observational Data Integration Towards Evaluation of water resources (APHRODITE; see text for details). The contour interval is $3 \mathrm{~mm} \cdot \mathrm{day}^{-1}$.

lous SST anomalies in the western tropical Pacific (Chen 2002). However, during the cold ENSO winter, the interaction between the East-Asian cold-air outflow and the tropical easterly disturbance often forms cold surge vortex, a major winter rain producer in the tropical south-southeast Asia. Impacts of the SSTs anomalies in the tropical Pacific on the rain-producing weather activities in tropical Southeast Asia during the extreme ENSO summer and winter through the large-scale anoma- 
lous circulations have been explored by some previous studies. Nevertheless, the possible interannual variation of rainfall during fall in Vietnam has not attracted too much research attention so far. Thus, it is our intent in this study to examine whether there is an interannual variation of this rainfall is caused by the ENSO cycle. According to the water vapor budget, precipitation is maintained by the divergence of water vapor flux (Chen 1985). The water vapor transport analysis is performed to search for the possible mechanism responsible for the interannual variation of rainfall in Vietnam. The data and computations of analysis are described in section 2. Major results of this study are presented in section 3. Concluding remarks are provided in section 4 .

\section{Data and computations}

\subsection{Data}

The primary rainfall datasets used in this study is: the rain-gauge based daily grid precipitation with a $0.25^{\circ} \times 0.25^{\circ}$ resolution compiled by the Asian Precipitation-Highly Resolved Observational Data Integration Towards Evaluation (APHRODITE) of water resources project: (http:// www.chikyu.ac.jp/precip). The compilation process of this dataset included observations made not only by the WMO stations, but also by stations available over the Asian monsoon region (including Bangladesh, Bhutan, Brunei, Cambodia, China, Indonesia, Israel, Kazakhstan, Malaysia, Nepal, Pakistan, the Philippines, Taiwan, Thailand and Vietnam) over the period of 1951-2007. The latest version APHRO_V1003R1 released to the public was used in this study. However, the detailed algorithm to produce this dataset is referred to Yatagai et al. (2009). Due to the quality of rainfall data during the Vietnam War, only the period of 1979-2007 were covered by our analysis.

Before finalizing the Science Plan of the EastAsian Monsoon Experiment (EAMEX) (Chen 2007) in the beginning of December 2007, central Vietnam experienced a severe flood during October-November of that year. Daily rainfall measurements at 163 stations in Vietnam over the entire year of 2007 were supplied by the National Hydrometeorological Service of Vietnam to the EAMEX so that a prelimimary test for the plan of the 2008 EAMEX field experiment can be done. Despite the fact these rain gauge observations covered only one year, these measurements also offer an opportunity to validate the APHRODITE's rainfall data.

The two aforementioned rainfall datasets only cover the land. In order to accomplish the water vapor transport analysis in global scale, both resolution of $2.5^{\circ} \times 2.5^{\circ}$ National Centers for Environmental Prediction-National Center for Atmospheric Research (NCEP-NCAR) reanalysis data (Kalnay et al. 1996) and the Climate Prediction Center (CPC) Merged Analysis of Precipitation (CMAP) data (Xie and Arkin 1997) were employed. Sea Surface Temperature (SST) compiled by the NCEP (Reynolds 1988; Reynolds and Marsico 1993), particularly the anomalies in the NINO3.4 region $\left(5^{\circ} \mathrm{S}-5^{\circ} \mathrm{N}, 120^{\circ} \mathrm{W}-170^{\circ} \mathrm{W}\right)$, will provide the ENSO episodes reference. All these analyses in this study were performed from 1979 to 2008.

\subsection{Computations}

Two diagnostic schemes are adopted in this study: The empirical orthogonal function (EOF) and water vapor budget analyses. The former is used to isolate the significant interannual climate mode of interest to the present study, while the latter is applied to illustrate the maintenance of rainfall interannual variation in central Vietnam during October-November.

The empirical orthogonal function (EOF) analysis is an effective means to isolate the significant climate modes from anomalies (departures from the mean values of a given field variable). The spatial structure of these modes can be depicted by the selected eigenvectors and their amplitudes and temporal evolutions are revealed through the eigencoefficient time series. Theoretical background and technical of the EOF analysis are well presented by Kutzbach (1967).

The vertically integrated water balance equation (Peixoto and Oort 1992) is

$$
\frac{\partial W}{\partial t}+\nabla \cdot Q=E-P
$$

where $W=\frac{1}{g} \int_{0}^{p_{s}} q d p, Q=\frac{1}{g} \int_{0}^{P_{s}} q V d p, E, P, g, q, p$, $p_{s}$ and $V$ are precipitable water, water vapor flux, evaporation, precipitation, gravity, specific humidity, pressure, surface pressure, and velocity vector, respectively. Following Chen (1985), the water vapor flux $Q$ can be divided into the rotational $\left(Q_{R}\right)$ and divergent $\left(Q_{D}\right)$ components, which can be measured in terms of horizontal gradients of streamfunction $\left(\psi_{Q}\right)$ and potential function $\left(\chi_{Q}\right)$, respectively, 


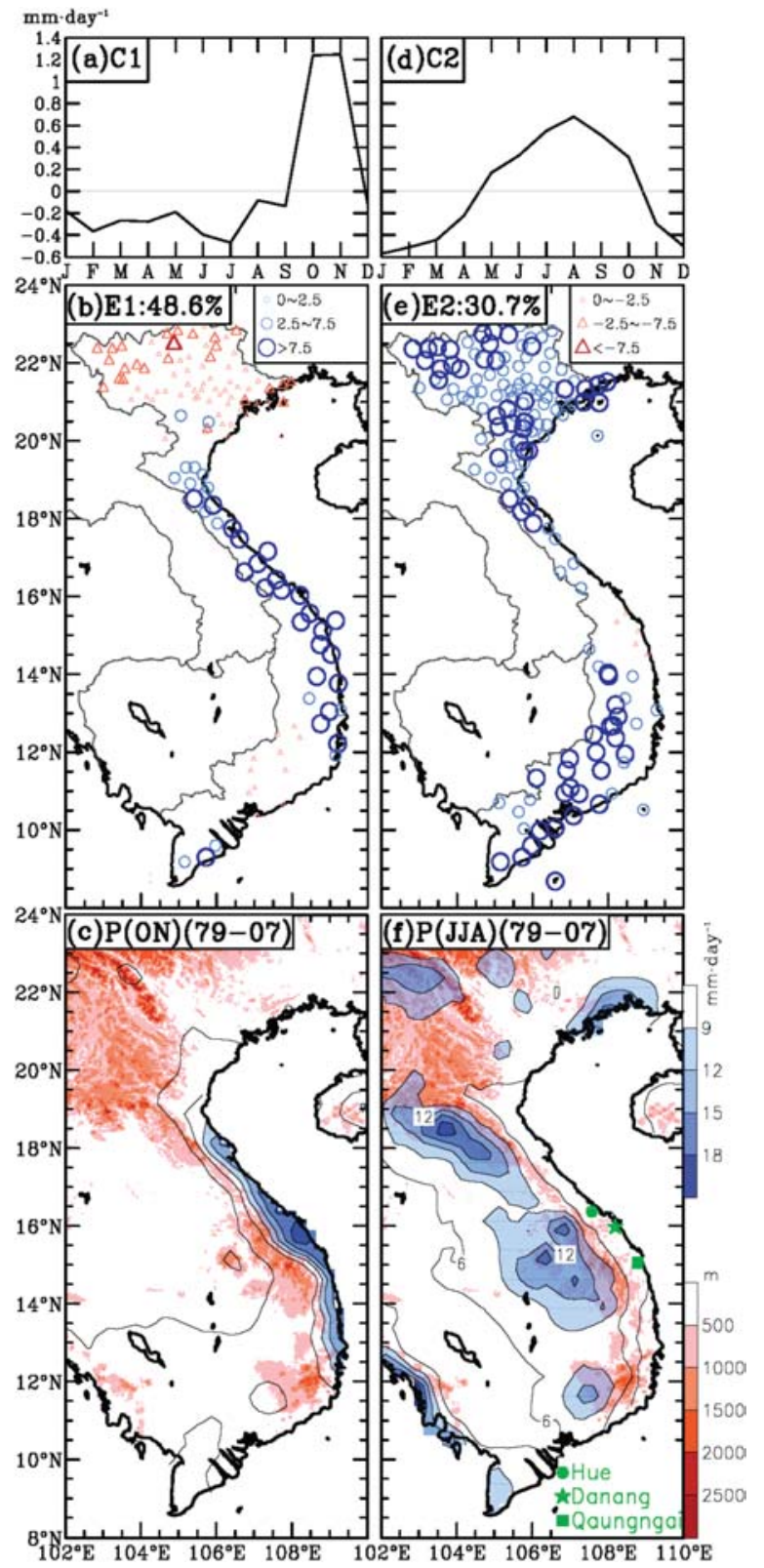

Fig. 2. The first two principal eigenmodes of rainfall measured at 163 stations for year 2007 obtained by the EOF analysis on monthly rainfall departures from their annual mean: Eigencoefficient time series are denoted by solid line in (a) $\mathrm{C} 1$ and (d) C2, while eigenvectors are marked by open circles for positive anomalies and open triangles for a negative anomalies in (b) E1 and (e) E2. Distributions of APHRODITE precipitation averaged over 29 years (1979-2007) for (c) October-November $P(\mathrm{ON})$, and (f) June-August $P(\mathrm{JJA})$.

$$
\begin{aligned}
& Q=Q_{R}+Q_{D}, \quad \text { and } \\
& Q_{R}=\hat{k} \times \nabla \psi_{Q} \quad \text { and } \quad Q_{D}=\nabla \chi_{Q}
\end{aligned}
$$

Because precipitation is maintained by divergence of water vapor flux, (1) can be written as,

$$
\frac{\partial W}{\partial t}+\nabla \cdot Q_{D}=E-P \text {. }
$$

We shall use interannual variation of the following hydrological variables, $\left(Q_{R}, W\right)$ and $\left(\chi_{Q}, Q_{D}, P\right)$ to illustrate how the interannual variation of rainfall is maintained.

\section{Results}

\subsection{Rainfall climatology}

It is revealed from the annual rainfall climatology depicted with the 29-year (1979-2007) APHRODITE precipitation (Fig. 1) that only in northern (north of $20^{\circ} \mathrm{N}$ ) and southern (south of $12^{\circ} \mathrm{N}$ ) Vietnam significant precipitation appears during summer months (May-August), but less in central Vietnam. On the contrary, the major rainfall occurs in central Vietnam during October-November. During this heavy rainfall season, central Vietnam frequently experiences the most severe flood events of the year. For instance, the total rainfall accumulation during October-November 2007 at Hue $\left(16^{\circ} 28^{\prime} \mathrm{N}, 107^{\circ} 36^{\prime} \mathrm{E}\right)$, Danang $\left(16^{\circ} 04^{\prime} \mathrm{N}, 108^{\circ} 14^{\prime} \mathrm{E}\right)$ and Quangngai $\left(15^{\circ} 07^{\prime} \mathrm{N}, 108^{\circ} 48^{\prime} \mathrm{E}\right)$ (marked by three different symbols in Fig. 2f) were 2,451, 2,307 and 2,125 $\mathrm{mm}$, respectively. According to the 2007 characteristics report from Vietnam National Centre for Hydro-Meteorological Forecasting (2008), more than $60 \%$ of the 2007 annual precipitation was generated at each station within these two months.

The 163 rain gauge observations in Vietnam for 2007 were originally analyzed to assess the strategic plan for the 2008 EAMEX heavy rainfall field experiment in fall. The by-product of this effort also serves as a way to validate the rainfall climatology generated from the APHRODITE gridded precipitation. After removing the annual averages of rain-

Three rainfall stations (see text for details): Hue (green dot), Danang (green star), and Quangngai (green square) are marked in (f). The contour interval of both $P(\mathrm{ON})$ and $P(\mathrm{JJA})$ is $3 \mathrm{~mm} \mathrm{day}^{-1}$. The color scale of orography in (c) and (f) is displayed in the lower-right corner of (f). 
fall at all 163 stations, we perform the EOF analysis with monthly rainfall departures. Displayed in Figs. $2(\mathrm{a}, \mathrm{d})$ and $(\mathrm{b}, \mathrm{e})$ are eigencoefficient time series $(\mathrm{C} 1$ and $\mathrm{C} 2)$ and eigenvectors (E1 and E2) of the first two principal eigenmodes. In view of variances explained by these two eigenmodes $(48.6 \%$ and $30.7 \%$, respectively), the seasonal variation of Vietnam rainfall is mostly be portrayed by them. Revealed from the temporal evolution of the Cs and the spatial structure of the Es, two distinct rainfall regimes emerge from this EOF analysis: the October-November regime in central Vietnam and the May-October regime in northern and southern Vietnam. Comparison between Figs. 2b and $2 \mathrm{c}$ reveals clearly that the spatial pattern of E1 resembles the distribution of the 29-year averaged October-November mean precipitation $P(\mathrm{ON})$ between $12^{\circ} \mathrm{N}$ and $19^{\circ} \mathrm{N}$ in central Vietnam. In the summer season, the structure of E2 (Fig. 2e) also spatially resembles $P(J \mathrm{JA})$ (Fig. 2f) with less rainfall occurred in central Vietnam whereas most precipitation appears on the windward side of the mountain range. Apparently, both the rain gauge observations and gauge-based gridded precipitation depict well these two rainfall regimes. The rainfall pattern without real station measurements presented by Chang et al. (2005) is also confirmed here by the rain gauge data analyzed by the current study. Furthermore, it is interesting to note that the Truong Son Range along the western border of Vietnam with Laos and Cambodia serves as a natural separation function for the October-November rainfall regime in central Vietnam from others.

The rainfall regimes of Vietnam can be summarized by a $y-t$ diagram of the rainfall averaged over a longitudinal zone of $1^{\circ}$ along the coastal line of Vietnam for the period of 1979-2007 generated with the $0.25^{\circ}$ longitude $\times 0.25^{\circ}$ latitude APHRODITE precipitation in Fig. 3a. Following the seasonal march, both northern and southern Vietnam clearly exhibit a rainfall maximum during summer except the southern tip of Vietnam where this maximum rainfall season also covers the fall. However, the northern rainfall maximum in summer gradually migrates southward to reach the OctoberNovember maximum in central Vietnam. The existence of this October-November rainfall regime could be substantiated by the coastal zone average of station rainfall of year 2007 as illustrated in Fig. $3 \mathrm{~b}$. In fact, the heavy rainfall in central Vietnam evidently appeared in 2007 and a possible mechanism will be suggested in the next section.
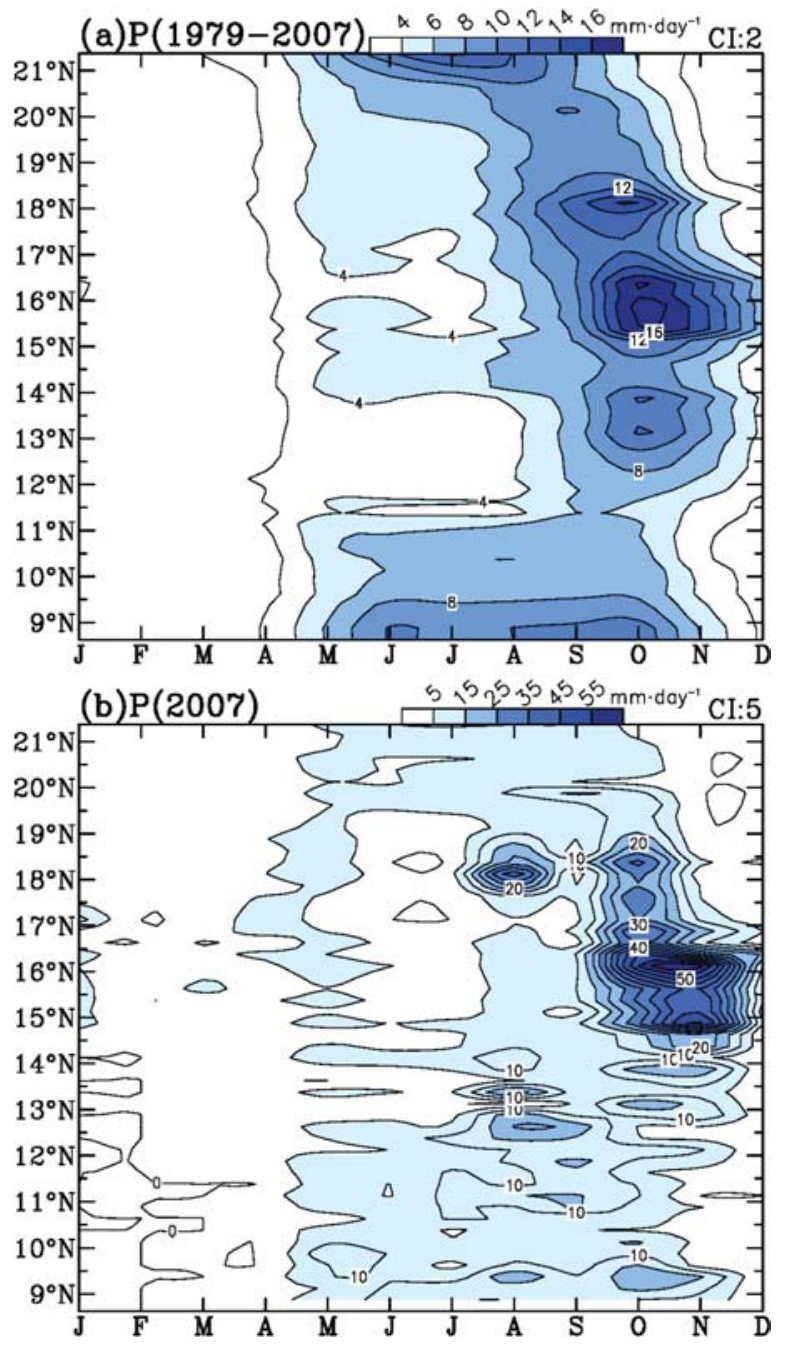

Fig. 3. The $y$ - $t$ diagram of rainfall (a) averaged over a longitudinal zone of $1^{\circ}$ (about $100 \mathrm{~km}$ from the coastal line) for the period of 1979-2007 with the APHRODITE precipitation, and (b) averaged station precipitation of year 2007 over a $1^{\circ}$ longitudinal zone along the coastline. The shading scales are displayed on the top middle of each corresponding panel. Contour intervals of precipitation in (a) and (b) are $2 \mathrm{~mm} \mathrm{~d}^{-1}$ and $5 \mathrm{~mm} \mathrm{~d}^{-1}$, respectively.

\subsection{Interannual variation of rainfall}

It was shown in Section 3 that the seasonal variation of rainfall of all 163 stations (Figs. 2a-b and $\mathrm{d}-\mathrm{e}$ ) that the October-November rainfall regime appears is the most significant seasonal variation mode over Vietnam, as indicated by the amplitude contrast between $\mathrm{C} 1$ and $\mathrm{C} 2$ time series and 


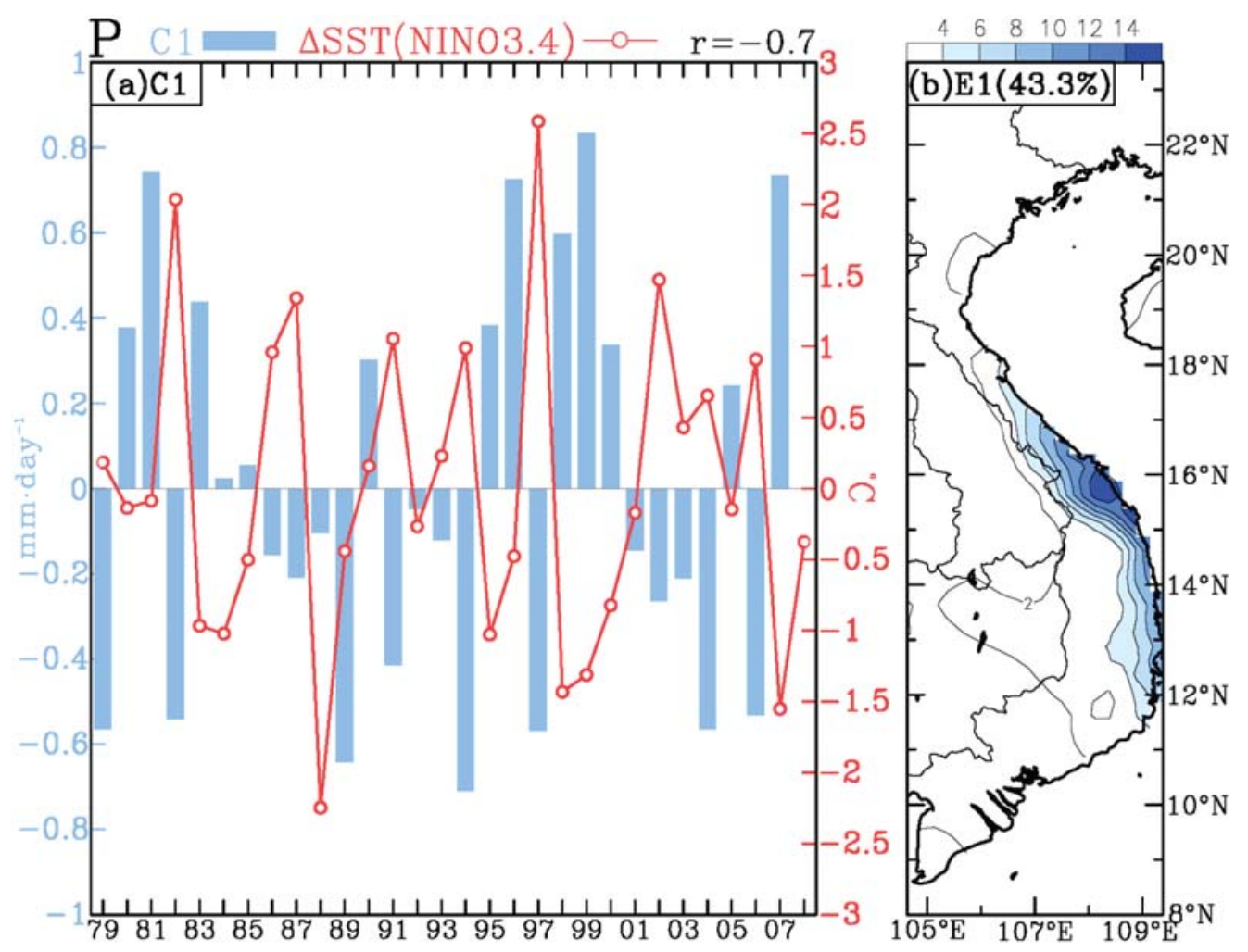

Fig. 4. (a) Eigencoefficient time series of the first eigenmode $\mathrm{C} 1$ (blue histogram) of the APHRODITE rainfall during October-November within the domain $\left(8^{\circ}-24^{\circ} \mathrm{N}, 104.75^{\circ} \mathrm{E}-109.25^{\circ} \mathrm{E}\right)$, and (b) the corresponding eigenvector E1. Note that the multiple-year (1979-2007) rainfall averages were removed before the EOF analysis was performed. The time series of October-November mean $\Delta S S T$ (NINO3.4) $[\equiv S S T$ (NINO3.4) - $\overline{S S T}(\mathrm{NINO3.4)}]$ is depicted by red line superimposed on C1 in (a). SST(NINO3.4) is October-November mean SST averaged over the NINO3.4 region $\left(5^{\circ} \mathrm{S}-5^{\circ} \mathrm{N}, 120^{\circ} \mathrm{W}-170^{\circ} \mathrm{W}\right)$ while $\overline{S S T}$ (NINO3.4) is the 30-year (1979-2008) mean value of SST(NINO3.4). The contour inverval of E1 is 2.

the spatial rainfall distribution along the narrow strip of central Vietnam of east of the Truong Son Range. However, one may wonder whether there is any rainfall interannual variability over this region. To answer this concern, the EOF analysis is performed with the October-November mean precipitation in the domain $\left(8^{\circ}-24^{\circ} \mathrm{N}, 104.75^{\circ}-109.25^{\circ} \mathrm{E}\right)$ after removing its multiple-year averages. Shown in Fig. 4 are the first eigenvector E1 and the corresponding eigencoefficient $\mathrm{Cl}$ time series. Superimposed in Fig. $4 \mathrm{a}$ is the time series of the October-November mean sea surface temperature departure, $\Delta S S T$ (NINO3.4) [ $\equiv S S T$ (NINO 3.4) $\overline{S S T}$ (NINO3.4)], where $S S T$ (NINO3.4) is the October-November mean SST averaged over the NOAA NINO3.4 area $\left(5^{\circ} \mathrm{S}-5^{\circ} \mathrm{N}, 120^{\circ} \mathrm{W}-170^{\circ} \mathrm{W}\right)$, and $\overline{S S T}$ (NINO3.4) is the multiple-year (19792008) mean value of $S S T$ (NINO3.4). Interestingly, the temporal variation of $\mathrm{C} 1$ (explained $43.3 \%$ variance) is almost out-of-phase with $\triangle S S T$ (NINO3.4). The correlation coefficient between $\mathrm{Cl}$ and $\Delta S S T$ (NINO3.4) is -0.7 . It is also surprising to see that the spatial structure of the eigenvector, E1, of rainfall anomalies within the domain shown in Fig. $4 \mathrm{~b}$ resembles the spatial distribution of the October-November rainfall climatology shown in Fig. $2 \mathrm{c}$ and the root-mean-square of rainfall departures from the October-November mean values averaged over the 1979-2007 period (not shown). It is inferred from the negative coherent correlation between $\mathrm{C} 1$ and $\triangle S S T$ (NINO3.4) that central Vietnam is drier (wetter) when SST over the NINO3.4 region is warmer (colder).

The most pronounced interannual variation of the global climate system is associated with the ENSO (Webster et al. 1998). Numerous studies 


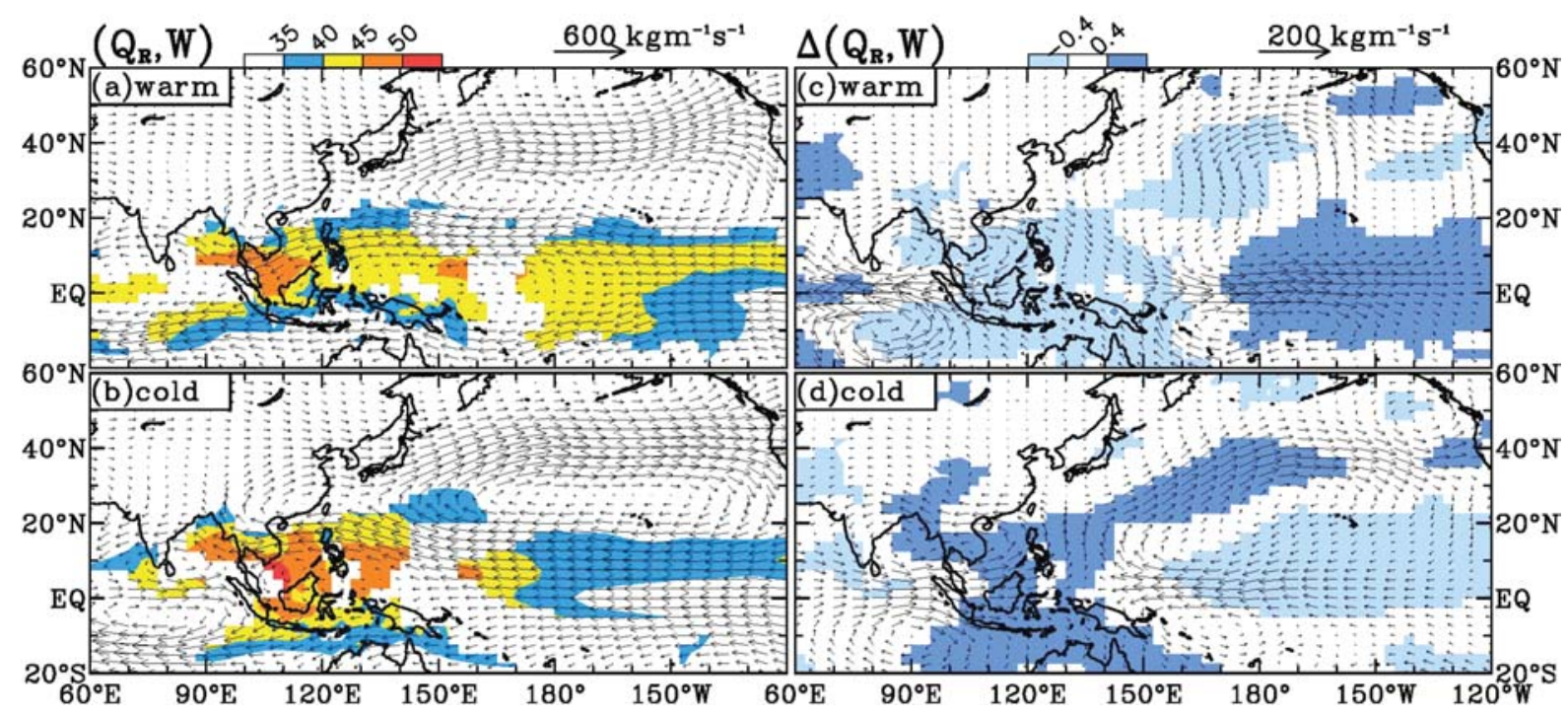

Fig. 5. The October-November composite charts for (a) warm years $\left(Q_{R}, W\right)$ (warm), (b) same as (a) except for cold years $\left(Q_{R}, W\right)$ (cold), and the composite departures from the 30-year (1979-2008) October-November mean for (c) warm years $\Delta\left(Q_{R}, W\right)$ (warm), (d) same as (c) except for cold years $\Delta\left(Q_{R}, W\right)$ (cold). Warm (cold) October-November in this study include 1982, 1986, 1987, 1991, 1994, 1997, 2002, and 2006 $\left(1983,1984,1988,1995,1998,1999\right.$, and 2007). $Q_{R}$ and $W$ are calculated from the National Centers for Environmental Prediction-National Center for Atmospheric Research (NCEP-NCAR) reanalysis data. The shaded areas indicate regions where $W$ and $\Delta W$ are statistically significant at $95 \%$ confidence level by student's $t$ test and their color scales are displayed on the top middle of corresponding panels.

(Philander 1990; Allan et al. 1996) have demonstrated that the ENSO is a response of atmospheric circulation to anomalous tropical Pacific SSTs. In addition, an ENSO episode generally emerges in fall and reaches its peak intensity in winter. The Climate Prediction Center adopts the SSTs over the NINO3.4 region in the tropical Pacific as one of the several operational indicators of ENSO activity. We thus use in this study the OctoberNovember $S S T$ (NINO3.4) as an oceanic thermal index. Let $\sigma$ represent the standard deviation of $\Delta S S T$ (NINO3.4) over 30 October-Novembers (1979-2008). The interannual variation of warm and cold fall during October and November is defined by the following criteria:

warm (October-November):

$$
\Delta S S T(\mathrm{NINO} 3.4) \geq 0.8 \sigma
$$

and

cold (October-November):

$\Delta S S T(\mathrm{NINO} 3.4) \leq-0.8 \sigma$.
Based on these criteria and $\Delta S S T$ (NINO3.4) (October-November) shown in Fig. 4a, OctoberNovember of $(1982,1986,1987,1991,1994,1997$, 2002, 2006) and October-November of (1983, 1984, 1988, 1995, 1998, 1999, 2007) are warm and cold, respectively.

Because water vapor exists primarily in the lower troposphere, the spatial structure of the $\psi_{Q}$ and $\chi_{Q}$ resembles those low-level streamfunction $(\psi)$ and velocity potential $(\chi)$ (Chen 1985). Although water vapor is primarily transported by the rotational component of water vapor flux $\left(Q_{R}\right)$ to the concerned region, but precipitable water is maintained by the divergent component of the water vapor flux, $Q_{D}$. The composite charts of $\left(Q_{R}, W\right)$ during warm and cold October-November are displayed in Figs. 5a, b, respectively. In cold years, W west of $150^{\circ} \mathrm{E}$ significantly increases, particularly off the coast of Vietnam over the South China Sea. Strong water vapor flux toward Vietnam is directing southwestward and almost perpendicular to the Truong Son Range (Fig. 5b). The interaction between the northeasterly water vapor flux and this mountain range forms an environment favorable for the 


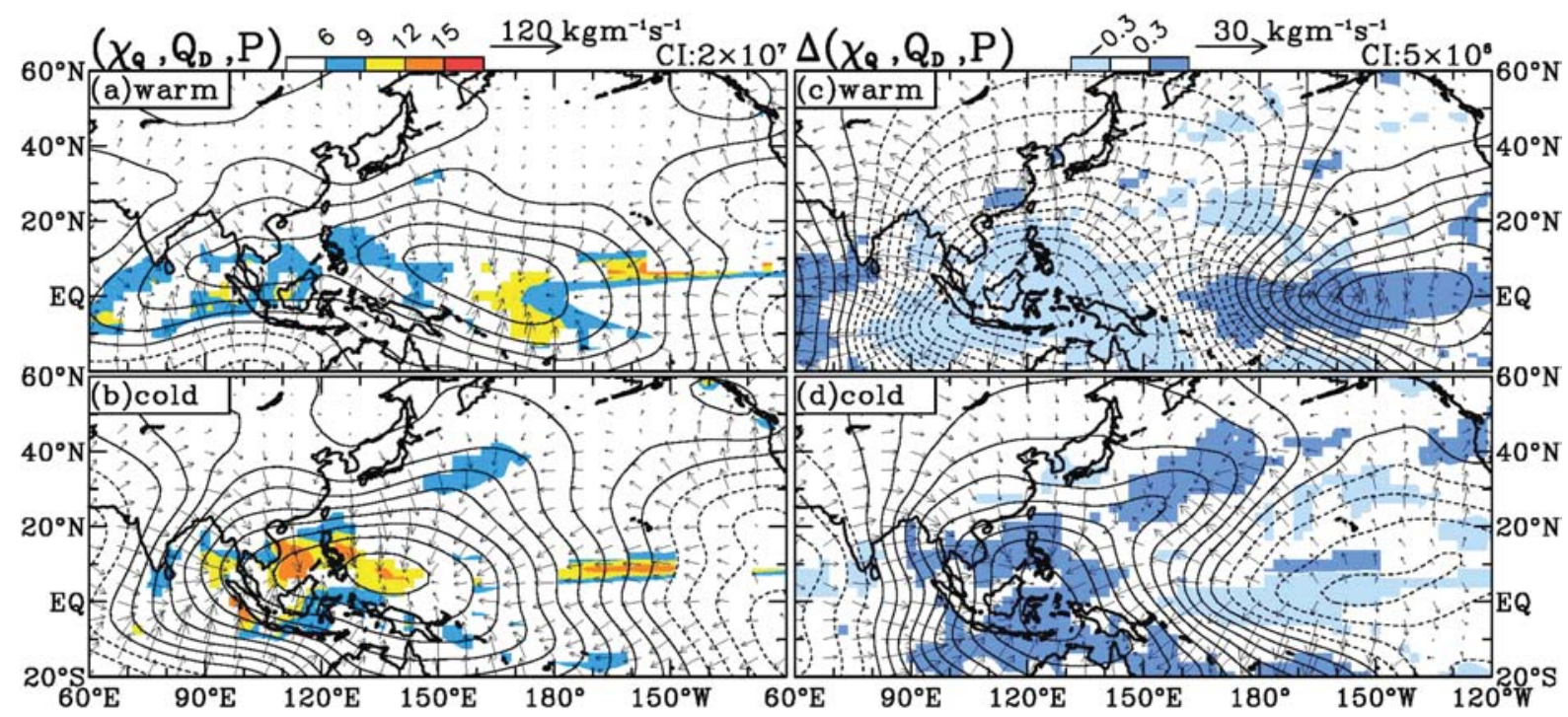

Fig. 6. The October-November composite charts for (a) $\left(\chi_{Q}, Q_{D}, P\right)$ (warm), (b) $\left(\chi_{Q}, Q_{D}, P\right)$ (cold), (c) $\Delta\left(\chi_{Q}, Q_{D}, P\right)$ (warm), and (d) $\Delta\left(\chi_{Q}, Q_{D}, P\right)$ (cold). Warm (cold) October-November in this study include 1982, 1986, 1987, 1991, 1994, 1997, 2002, and 2006 (1983, 1984, 1988, 1995, 1998, 1999, and 2007). $\chi_{Q}$ and $Q_{D}$ are calculated from NCEP-NCAR reanalysis data while $P$ is generated from the Climate Prediction Center (CPC) Merged Analysis of Precipitation (CMAP) data. The shaded areas indicate regions where $P$ and $\Delta P$ are statistically significant at $95 \%$ confidence level by student's $t$ test and their color scales are displayed on the top middle of corresponding panels.

orographically-induced precipitation. On the contrary, during warm years, water vapor flux is weaker and its direction is more southward and paralleled with the Truong Son Range. This relationship between water vapor flux and the mountain range does not establish an environment favorable for the interaction between water vapor flux and mountain to enhance rainfall (Fig. 5a). This argument is illustrated further by Figs. 5c, d. An anomalous cyclonic (anticyclonic) cell of water vapor flux appears in south Asia is paired with an anomalous anticylonic (cyclonic) circulation cell over the western north Pacific during cold (warm) episodes. The water vapor transported by these two anomalous circulations is convergent toward (divergent out of) the South China Sea and the Philippine Sea west of $150^{\circ} \mathrm{E}$ during cold (warm) years. In turn, the anomalous cyclonic (anticyclonic) circulation over south Asia enhances (reduces) the water vapor supply toward Indochina Peninsula, particular Vietnam.

According to Eq. (3), precipitation should be maintained by the convergence of water vapor flux. Thus, an increase (decrease) of precipitation is accompanied by the enhancement (reduction) of convergent water vapor flux. Illustrated in Figs. $6 \mathrm{a}, \mathrm{b}$ are composite charts of $\left(\chi_{Q}, Q_{D}, P\right)($ OctoberNovember) during warm and cold OctoberNovembers, respectively. During cold (warm) years, the $\chi_{Q}$ field is enhanced (weakened) over the South China Sea and the Philippine Sea while convergence of water vapor flux and precipitation significantly increase (decrease) over this region, including Vietnam. It appears that an interannual seesaw of the anomalous divergent water vapor flux $\Delta\left(\chi_{Q}, Q_{D}, P\right)$ (Figs. 6c, d) converges (diverges) water vapor toward (out of) the Southeast Asian monsoon region to maintain excessive (deficient) rainfall during cold (warm) episodes. This interannual variation of the divergent water vapor flux is a result of the divergent circulation in response to tropical Pacific SST anomalies. To explore the further details of the interannual rainfall variation in Vietnam, the rainfall composite charts over Vietnam during warm and cold October-Novembers are shown in Fig. 7. The rainfall in central Vietnam is much more during cold years than warm years. It was pointed out previously that heavy rainfall 


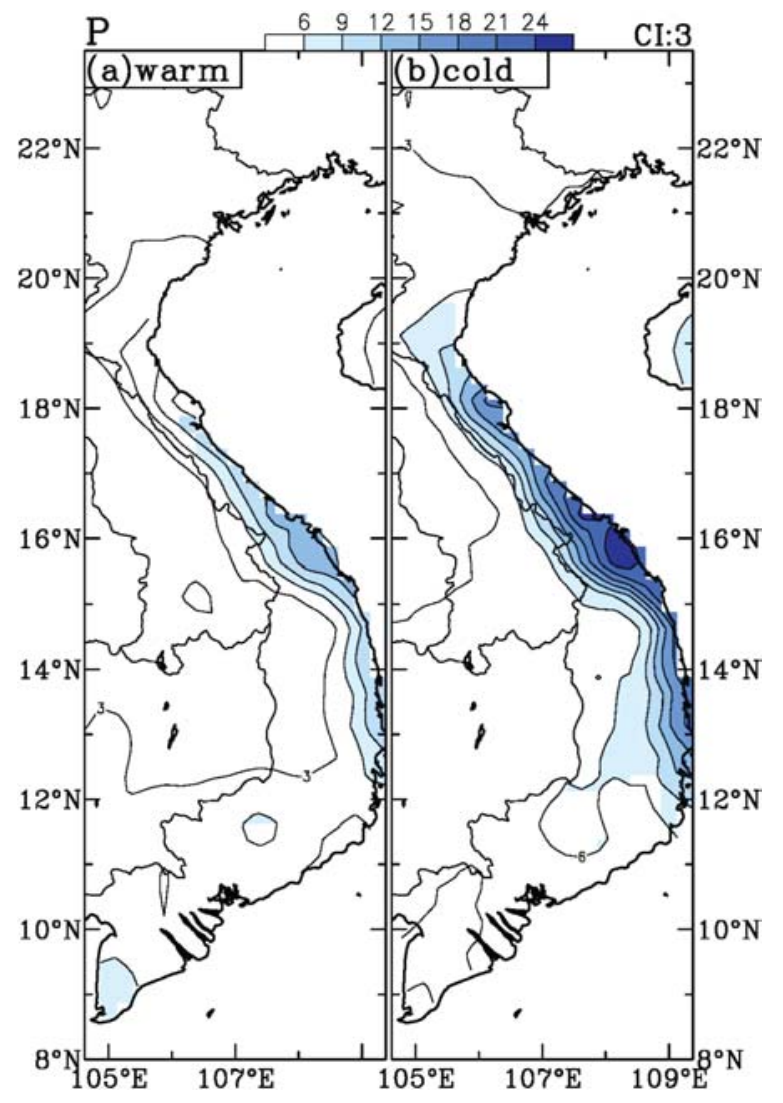

Fig. 7. Composite rainfall distribution for (a) $P$ (warm) (averaged over 1982, 1986, 1987, 1991, 1994, 1997, 2002, and 2006), and (b) $P$ (cold) (averaged over 1983, 1984, 1988, 1995, 1998, 1999, and 2007) generated from the APHRODITE precipitation. The shaded areas indicate regions where $P$ are statistically significant at $95 \%$ confidence level by student's $t$ test and the color scale is provided in the middle top of these two panels.

had occurred in central Vietnam during OctoberNovember 2007, for example. As revealed from Fig. 4a, October-November of year 2007 belongs to a cold episode. Both rotational (Fig. 5) and divergent (Fig. 6) water vapor flux during cold years are enhanced to maintain the excessive rainfall in central Vietnam in 2007.

\section{Concluding remarks}

Due to limited surface stations, Vietnam, a tropical country whose terrain has large longitudinal extent located at the east coast of Indochina Peninsula, is demanding a comprehensive picture of rainfall variation. The rain-gauge based daily grid precipitation with a $0.25^{\circ} \times 0.25^{\circ}$ horizontal data was compiled and released recently by the Asian Precipitation-Highly Resolved Observational Data Integration Towards Evaluation of water resources (APHRODITE) Project. This dataset was analyzed to depict the rainfall climatology of Vietnam. The rain gauge measurements of 163 stations in Vietnam for year 2007 were provided by the National Hydrometeorological Service of Vietnam. These station measurements were used not only to validate the analysis results using the APHRODITE data, but to verify two distinct rainfall regimes: the October-November regime in central Vietnam, the May-October regime in the northern and southern part of this country. It appears that the Truong Son Range along the western border of Vietnam with Laos and Cambodia provides a natural separation between the October-November rainfall in central Vietnam, covering $12^{\circ} \mathrm{N}-19^{\circ} \mathrm{N}$, and other regimes.

The interannual variation of the central Vietnam rainfall during October-Novermber is well depicted by an EOF mode which exhibits a clear variation out of phase with the SST(NINO3.4) index. The correlation coefficient between these two interannual variations is -0.7 . It is inferred from this negatively correlated relationship that it is drier (wetter) in central Vietnam when SST over the NINO3.4 region is warmer (colder). The water vapor transport analysis shows that an anomalous cyclonic (anticyclonic) circulation over south Asia is paired with an anomalous anticylonic (cyclonic) circulation over the western north Pacific during cold (warm) episode. The water vapor is converged (diverged) by these two anomalous circulations toward (out of) the South China Sea and the Philippine Sea west of $150^{\circ} \mathrm{E}$ during cold (warm) years. In turn, the anomalous cyclonic (anticyclonic) circulation over south Asia enhances (reduces) the water vapor supply toward Indochina Peninsula, particular Vietnam. Also, an interannual east-west seesaw of the anomalous divergent water vapor flux $\Delta\left(\chi_{Q}, Q_{D}, P\right)$ converges (diverges) water vapor toward (out of) this concerned region to maintain excessive (to reduce) rainfall during cold (warm) episodes. Evidently, the interannual variation of the divergent water vapor flux induced by tropical Pacific SST anomalies can contribute to the interannual variation of central Vietnam OctoberNovember rainfall. 


\section{Acknowledgements}

This study is part of the research effort under the East Asian Monsoon Experiment (EAMEX) in collaboration with the Monsoon Asian HydroAtmosphere Scientific Research and Prediction Initiative (MAHASRI) and the National HydroMeteorological Services of Vietnam, and supported by the NSC99-2111-M-008-012 of Taiwan. We would like to thank professor Jun Matsumoto of Tokyo Metropolitan University for motivating us to explore the cause of the Vietnam fall rainfall interannual variation. We thank Dr. Akiyo Yatagai of Research Institute for Humanity and Nature for providing us the daily grid precipitation compiled by the Asian Precipitation-Highly Resolved Observational Data Integration Towards Evaluation (APHRODITE) of water resources project. Comments and suggestions offered by two reviewers are very helpful in improving this paper. Typing supports provided by Ms. Mei-Chu Yen and Mr. Jenq-Dar Tsay are highly appreciated.

\section{References}

Allan, R., J. Lindesay, and D. Parker, 1996: El Niño Southern Oscillation and Climate Variability. CSIRO Publishing, 405 pp.

Chang, C.-P., Z. Wang, J. McBride, and C.-H. Liu, 2005: Annual cycle of Southeast Asia-maritime continent rainfall and the asymmetric monsoon transition. J. Climate, 17, 3141-3155.

Cheang, B.-K., 1987: Short- and long-range monsoon prediction in Southeast Asia. Fein, J. S. and P. L. Stephens (eds.), Monsoons, John Wiley \& Sons, 579-606.

Chen, T.-C., 1985: Global water vapor flux and maintenance during FGGE. Mon. Wea. Rev., 113, 18011819.

Chen, T.-C., 2002: A north Pacific short-wave train during the extreme phases of ENSO. J. Climate, 15, 2359-2376.

Chen, T.-C., and S.-P. Weng, 1998: Interannual variation of the summer synoptic-scale disturbance activity in the western tropical Pacific. Mon. Wea. Rev., 126, 1725-1733.

Chen, T.-C., and S.-P. Weng, 1999: Interannual and intraseasonal variations in monsoon depressions and their westward-prpagating predecessors. Mon. Wea. Rev., 127, 1005-1020.

Chen, T.-C., and J.-H. Yoon, 2000: Interannual variation in Indochina summer monsoon rainfall: possible mechanism. J. Climate, 13, 1979-1986.

Chen, T.-C., S.-Y. Wang, W.-R. Huang, and M.-C. Yen, 2004: Variation of the East Asian summer monsoon rainfall. J. Climate, 17, 744-762.
Chen, T.-C., S.-P. Weng, N. Yamazaki, and S. Kiehne, 1998: Interannual variation in the tropical cyclone formation over the western North Pacific. Mon. Wea. Rev., 126, 1080-1090.

Chen, T.-C., M.-C. Yen, J.-D. Tsay, T. T. T. Nguyen, and J. Alpert, 2011: Synoptic development of the Hanoi heavy rainfall/flood event during 30-31 October 2008: Multiple-scale processes. Mon. Wea. Rev. (submitted).

Kalney, E., and Coauthors, 1996: The NCEP/NCAR 40Year Reanalysis Project. Bull. Amer. Meteor. Soc., 77, 437-471.

Kutzbach, J. E., 1967: Empirical eigenvectors of sea-level pressure, surface temperature, and prediction complexes over North America. J. Appl. Meteor., 6, 791-802.

Matsumoto, J., 1997: Seasonal transition of summer rainy season over Indochina and adjacent monsoon region. Adv. Atmos. Sci., 14, 231-245.

Nguyen, T. D., C. Uvo, and D. Rosbjerg, 2007: Relationship between the tropical Pacific and Indian Ocean sea-surface temperature and monthly precipitation over the central highlands, Vietnam. Int. J. Climatol., 27, 1439-1454.

Nitta, T., 1987: Convective activities in the tropical western Pacific and their impact on the Northern Hemisphere circulation. J. Meteor. Soc. Japan, 65 , 373-390.

Philander, G. S., 1990: El Niño, La Niña, and the Southern Oscillation. Academic Press, 293 pp.

Ramage, C. S., 1952: Variation of rainfall over south China through the wet season. Bull. Amer. Meteor. Soc., 33, 308-311.

Reynolds, R. W., 1988: A real-time global sea surface temperature analysis. J. Climate, 1, 75-86.

Reynolds, R. W., and D. C. Marscio, 1993: An improved real-time global sea surface temperature analysis. J. Climate, 6, 114-119.

Truong, N. M., T. T. Tien, R. A. Pielke Sr., C. L. Castro, and G. Leoncini, 2009: A modified KainFritsch scheme and its application for the simulation of an extreme precipitation event in Vietnam. Mon. Wea. Rev., 137, 766-789.

Vietnam National Centre for Hydro-Meteorological Forecasting, 2008: Characteristics of HydroMeteorology in the year 2007, 105pp. (in Vietnamese) [Available from the Vietnam National Centre for Hydro-Meteorological Forecasting, No. 4, Dang Thai Than street, Hoan Kiem District, Hanoi city, Vietnam].

Wang, B., R. Wu, and X. Fu, 2000: Pacific-East Asian teleconnection: How does ENSO affect East Asian climate? J. Climate, 13, 1517-1536.

Xie, P., and P. A. Arkin, 1997: Global precipitation: A 17-year monthly analysis based upon gauge observations, satellite estimates, and numerical model outputs. Bull. Amer. Meteor. Soc., 78, 2539-2558. 
Yatagai, A., O. Arakawa, K. Kamiguchi, H. Kawamoto, M. I. Nodzu, and A. Hamada, 2009: A 44-year daily gridded precipitation dataset for Asia based on a dense network of rain gauges. SOLA, 5, 137140.

Yokoi, S., and J. Matsumoto, 2008: Collaborative effects of cold surge and tropical depression-type disturbance on heavy rainfall in central Vietnam. Mon. Wea. Rev., 136, 3275-3287.
Yokoi, S., T. Satomura, and J. Matsumoto, 2007: Climatological characteristics of the intraseasonal variation of precipitation over the Indochina Peninsula. J. Climate, 20, 5301-5315.

Zhang, Y., T. Li, B. Wang, and G. Wu, 2002: Onset of the summer monsoon over the Indochina Peninsula: Climatology and interannual variations. $J$. Climate, 15, 3206-3221. 